\title{
Effects of Vernonia amygdalina Del. Extract on Cholesterol Level and Lipid Peroxidation Status in Rats Given Red Dye Adulterated Palm Oil
} Diets

\author{
Imafidon E. Kate ${ }^{1}$ and Okunrobo O. Lucky ${ }^{2^{\star}}$ \\ ${ }^{1}$ Department of Biochemistry, Faculty of Life Sciences, University of Benin, Benin City, \\ 300001, Edo State, Nigeria. \\ ${ }^{2}$ Pharmaceutical Chemistry Department, Faculty of Pharmacy, University of Benin, \\ Benin City, 300001, Edo State, Nigeria.
}

\section{ABSTRACT}

Aims: To evaluate the effects of aqueous extract of $V$. amygdalina on lipid profile and lipid peroxidation status in rats.

Study Design: Experimentation.

Place and Duration of Study: Departments of Biochemistry and Pharmaceutical Chemistry, University of Benin, Benin city, Nigeria. From February, 2011 to November, 2011.

Methodology: Biochemical analyses were carried out to determine the activities of liver and plasma catalase, superoxide dismutase (SOD) and levels of malondialdehyde, total cholesterol, high density lipoprotein (HDL) and low density lipoprotein (LDL) cholesterol. Consequently, forty-eight rats were divided into six groups of eight rats each; the first group of animals was fed on rats' chow only while others were given $90 \%$ rats' chow supplemented with $10 \%$ palm oil. Solvent red 24 was administered in the diet to provide levels of $0 \%(\mathrm{PO} / \mathrm{GM}) .0 .005 \%(\mathrm{PO} / 0.005), 0.01 \%(\mathrm{PO} / 0.01)$ and $0.015 \%(\mathrm{PO} / 0.015)$. The sixth group of animals was given $0.015 \%$ dye along with $200 \mathrm{mg} / \mathrm{kg}$ extract of $V$. amygdalina. The animals were given these diets for six weeks along with water ad libitum. Results: There were reductions in catalase activities at all dose levels of dye administration and significant $(P<0.05)$ increase in SOD and malondialdehyde levels in those groups administered with $0.015 \%$ dye (PO/0.015). These effect was significantly ameliorated on administration of the $V$. amygdalina extract. LDL-Cholesterol levels was significantly increased and HDL-Cholesterol reduced at all levels of dye administration, 
this effect was significantly ameliorated in the PO/BL group on administration of $V$. amygdalina.

Conclusion: Administration of different dose of solvent red 24 dye increased lipid peroxidation status and LDL-Cholesterol levels in rats, these effects were ameliorated on administration of $200 \mathrm{mg} / \mathrm{kg} \mathrm{V}$. amygdalina aqueous extract.

Keywords: Vernonia amydalina; palm oil diet; solvent red 24; lipid peroxidation; rats.

\section{INTRODUCTION}

Strong correlations have been shown between increased plasma total cholesterol and low density lipoprotein cholesterol and increased incidence of coronary heart diseases (Edem, 2002). The cardio protective nature of leaf supplements has been reported; the methanolic extract of $V$. amygdalina has been shown to have a lipid lowering effects (Adaramoye et al., 2008; Ekpo et al., 2007). Research has shown that oxidative stress is involved in the development of over a hundred pathologies, many chronic diseases and causes of food spoilage are linked to pro-oxidant (ljeh and Ejike, 2011). A study by (Owolabi et al., 2008) showed that both ethanolic and aqueous extract of $V$. amygdalina have potent antioxidant abilities, the extracts were found to inhibit bleaching by $\beta$-carotene, oxidation of linoleic acid and lipid peroxidation induced by $\mathrm{Fe}^{2+} /$ ascorbate in rat liver microsomal preparations.

V. amygdalina (bitter leaf) is a widely used local plant in Nigeria. It is used for both therapeutic and nutritional purposes. Igile et al. (1994) reported that in traditional medicine, practitioners use the plant as an antihelminth, antimalarial and as a laxative, it is also use as a digestive tonic, appetizer, febrifuge and for the treatment of topical wounds (Iwu, 1986). A wide array of phytochemicals have been shown to be present in $V$. amygdalina some of these phytochemicals include steroidal saponin, sesquiterpene lactones, flavonoids (Udensi et al., 2002; Tona et al., 2004). Other phytochemicals present in the leaves are terpenes, coumarins, phenolic acids, lignans, xanthones and anthraquinones Izevbigie (2003).

Solvent red 24 (sudan IV, scarlet red) is a lysochrome diazo dye often used in coloring plastic, waxes, oils, fats etc. As food dye, solvent red 24 is considered an illegal dye, mainly because of its harmful effect over a long period of time. However, in some developing countries of the world, the legislature banning the use of this dye is not properly enforced. Many palm oil producers use solvent red 24 as an additive to improve the color and market value of improperly processed palm oil. Much work has been done on the carcinogenicity of synthetic dyes. Tsuda et al. (2001) observed colon DNA damage associated with intake of three azo dyes, amaranth (Red 2), allura red (Red 40) and acid red. Dees et al. (1997) reported that Red No. 3, which has estrogen like growth stimulatory properties, could be a significant risk factor in human breast carcinogenesis.

Palm oil is a major component of most Nigerian diets; these are often taken alongside vegetables such as $V$. amygdalina, Telferia occidentalis, Talinum triangulare, etc. Palm oil obtained from the fruit of the oil palm tree (Elaies guineensis) is the most widely produced edible vegetable oil in the world today Chondrassekharan et al. (2000), it is a common cooking ingredient in the tropical belt of Africa, South East Asia and parts of Brazil. V. amygdalina (bitter leaf) is a shrub with petiolate leaf of about $6 \mathrm{~mm}$ diameter, It has green 
leaves with a bitter taste. Some work has been done on the anticarcinogenic effect of this plant Izevbigie et al. (2004). This study investigates the effect of this dye and $V$. amygdalina on cholesterol levels and lipid peroxidation status in rats.

\section{MATERIALS AND METHODS}

\subsection{Sources of Materials/Animals}

Forty - eight albino rats used for this study were obtained from the animal house of Ambrose Alli University, Ekpoma, Edo State, Nigeria. The rats' chows used were products of Edo Feed and Flour Mills, Limited, Ewu, Edo State. Palm oil was obtained from Palm Oil Research Company (PRESCO), Edo State, Nigeria and Solvent red 24 was procured from a standard chemical shop, Silveb Scientific Nigeria Limited, Lagos State, Nigeria. The chow contains; crude protein, $14.50 \%$, crude fat, $4.80 \%$, crude fibre, $7.20 \%$, crude ash, $8.00 \%$, calcium, $0.80 \%$, phosphorus, $0.52 \%$, sodium, $0.15 \%$, lysine, $0.60 \%$, methionine, $0.29 \%$, vitamin $\mathrm{E}, 15 \mathrm{mg}$, vitamin $\mathrm{B} 2,4 \mathrm{mg}$, vitamin $\mathrm{C}, 50 \mathrm{mg}, \mathrm{Mn}, 30 \mathrm{mg}, \mathrm{Zn}, 30 \mathrm{mg}$. Bitter leaf was obtained at a local market in Edo State, Nigeria.

\subsection{Extraction of Plant Material}

$V$. amygdalina (bitter leaf) leaves were rinsed and sundried for three days. The dried leaves was pulverized into powder and sieved. $150 \mathrm{~g}$ of the powder was macerated in $1.5 \mathrm{~L}$ of water at room temperature, and allowed to stand for 24 hours. After 24 hours a muslin cloth was used in sieving the liquid extract. The filtrate was evaporated to dryness at room temperature in a rotary evaporator. $4 \mathrm{~g}$ of the extract was dissolved in $100 \mathrm{ml}$ of water.

\subsection{Treatment of Animals}

Forty-eight albino rats were divided into six groups of eight rats each. They were acclimatized for 2 weeks on rats' chow and water ad libitum. The first group (GM) was given $100 \%$ rats' chow while the other groups were given $90 \%$ rats' chow supplemented with $10 \%$ palm oil. Solvent red 24 was administered in the diet to provide levels of $0 \%$ (PO/GM), $0.005 \%$ (PO/0.005), $0.01 \%(\mathrm{PO} / 0.01)$ and $0.015 \%(\mathrm{PO} / 0.015)$. The animals were given these diets for six weeks along with water, ad libitum. They were weighed weekly, feed intake was estimated daily. The animals were properly housed in well ventilated cages. Ethical approval was obtained from the Animals Use and Ethics Committee of the Faculty of Pharmacy, University of Benin, Benin City, Nigeria.

\subsection{Collection of Samples}

The rats were subjected to an overnight fast, after which they were anaesthetized and blood collected by cardiac puncture into containers with or without anticoagulants. The Liver was excised, washed in ice-cold saline, blotted dry and placed in plain containers. Liver homogenate was prepared in phosphate buffer, $0.1 \mathrm{M}, \mathrm{pH} 7.4$ and used for e biochemical analyses.

\subsection{Chemicals}

All chemicals used in the study were of analytical grade (Aldrich Chemicals- Germany). 


\subsection{Methodology}

Biochemical analyses were carried out to determine the activities of catalase, superoxide dismutase (SOD) and levels of malondialdehyde (MDA), cholesterol, LDL cholesterol and HDL cholesterol levels. Catalase activity was determined by the method of Sinha (1972) and superoxide dismutase (SOD) activity was determined by the method of Misra and Fridovic, 1972. Malondialdehyde (MDA) levels were measured by the method of Gutheridge and Wilkin, 1982. Total cholesterol and HDL - Cholesterol levels were estimated using analytical kits (Quimica Clinica Applicada Laboratories, Spain). Total cholesterol was estimated using the Chod - Pap method Zoppi and Fellini, 1976, HDL cholesterol by the dextran Sulphate Mg II method Wieland and Siedel, 1981. The equation of Friedewald, et al. (1972) was used to estimate LDL cholesterol concentration.

\subsection{Statistical Analysis}

All values were expressed as mean \pm SEM. One way analysis of variance was used to test for difference among all the groups. Duncan's multiple range tests was used to test for significant differences among the means. A $p-$ value of $<0.05$ was considered statistically significant.

\section{RESULTS AND DISCUSSION}

There was significant $(\mathrm{P}<0.05)$ weight loss associated with rats in the $\mathrm{PO} / 0.015$ group. But there was no weight loss in the group administered $0.015 \%$ dye alongside $200 \mathrm{mg} / \mathrm{kg}$ extract of $V$. amygdalina leaves (PO/BL). Weight gain was observed in other groups of rats.

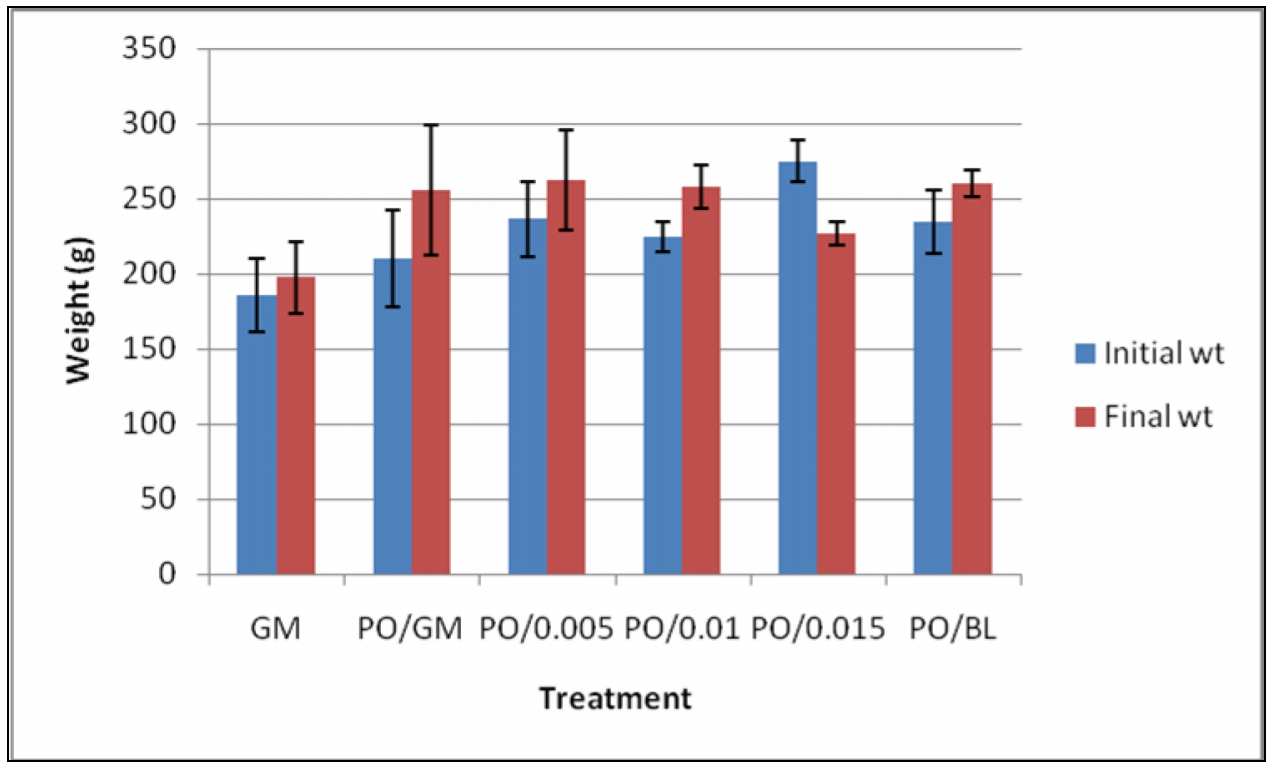

Fig. 1. Initial and final body weight of rats administered red dye adulterated palm oil diets and $V$. amygdalina extract 
Feed intake was significant reduced in the $\mathrm{PO} / 0.005$ and $\mathrm{PO} / 0.01$ groups of rats and in those administered $0.015 \%$ of dye alongside $V$. amygdalina extract $(\mathrm{PO} / \mathrm{BL})$ compared with control (PO/GM).

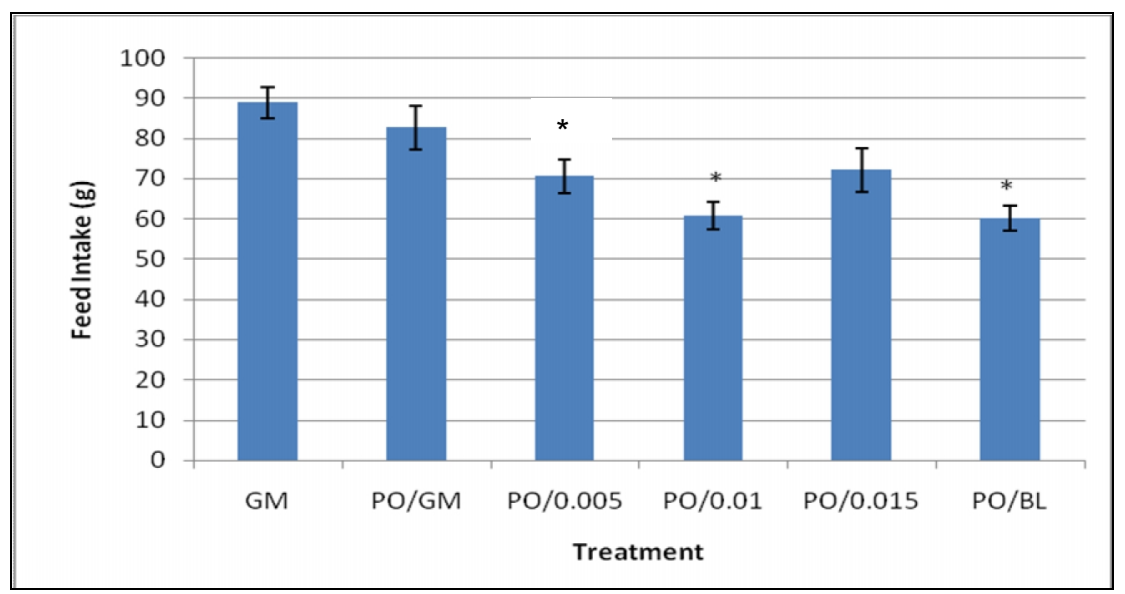

Fig. 2. Effects of red dye adulterated palm oil diets and aqueous extract of $\boldsymbol{V}$. amygdalina on feed intake

(significance at $p<0.05$ compared with $P O / G M$ ).

Liver and plasma catalase activities were significantly reduced in those groups administered the dye compared with control (PO/GM). However, there were significant increases in liver and plasma catalase activities in those groups administered $0.015 \%$ dye alongside the $V$. amygdalina extract (PO/BL) compared with those groups administered $0.015 \%$ dye without the extract $(\mathrm{PO} / 0.015)$.

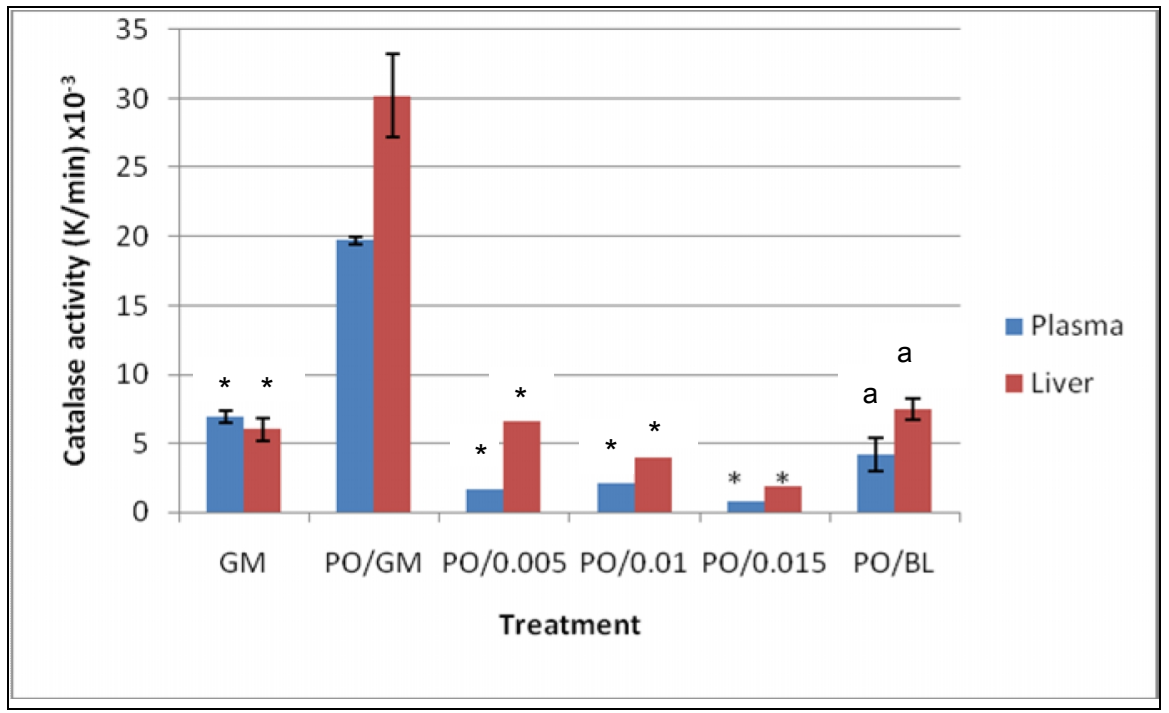

Fig. 3. Effects of red dye adulterated palm oil diets and $V$. amygdalina extract on catalase activity in the liver and plasma of rats

( $a$ = significance at $p<0.05$ compared with $P O / 0.015$, significance at $p<0.05$ compared with control; $P O / G M)$. 
Superoxide dismutase activity in the plasma of rats in the $\mathrm{PO} / 0.005$ and $\mathrm{PO} / 0.01$ groups were not significantly altered compared with control, but liver SOD activities were significantly reduced. Rats in the PO/0/015 groups had significantly higher plasma and significantly reduced liver SOD activities. These effects were ameliorated in the rats administered the extract.

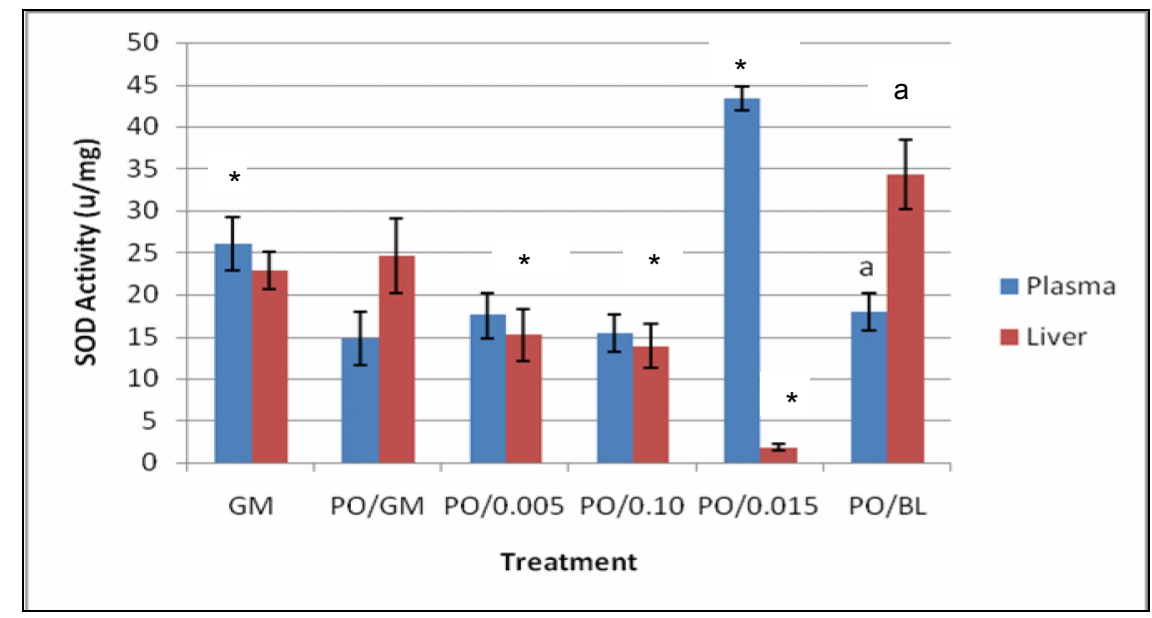

Fig. 4. Effects of red dye adulterated palm oil diets and $V$. amygdalina on superoxide dismutase activity in the liver and plasma

( $a=$ significance at $p<0.05$ compared with PO/0.015, ${ }^{*}$ significance at $p<0.05$ compared with $P O / G M$ control).

Increase in malondialdelyde levels observed in the $\mathrm{PO} / 0.005$ and $\mathrm{PO} / 0.01$ groups were significant. Significant increase was also observed in the PO/0.015 group. This effect was ameliorated by the administration of $V$. amygdalina extract.

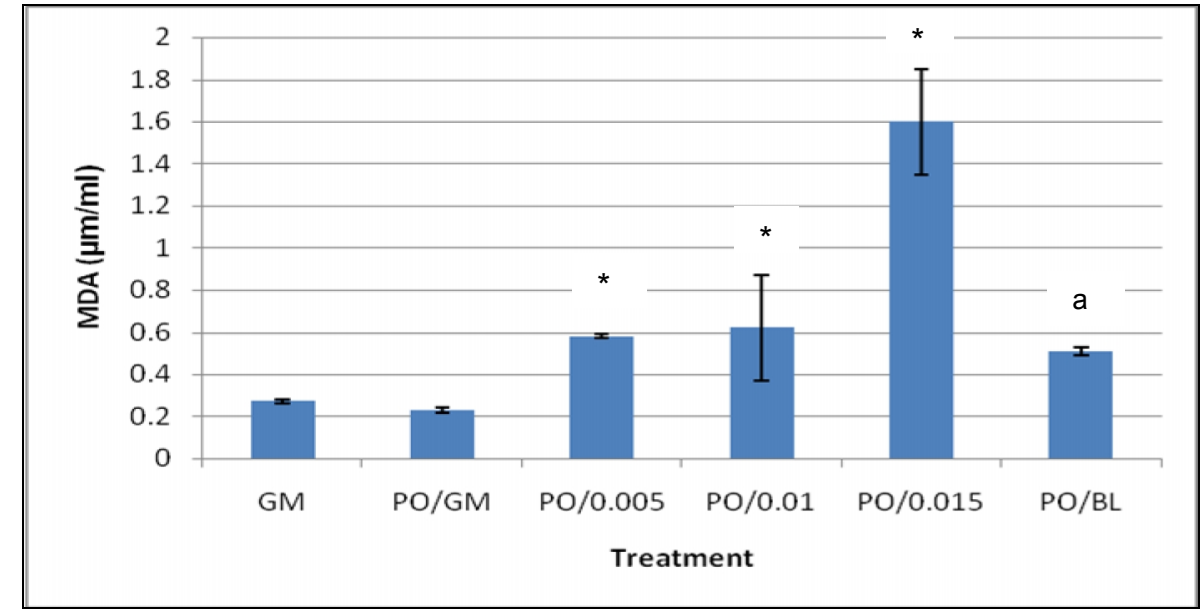

Fig. 5. Effect of red dye adulterated palm oil diets and $V$. amygdalina extracts on malondiadelyde levels

( significance at $p<0.05$ compared with control, $a=$ significance compared with $P O / 0.015$ ). 
Cholesterol levels of the rats in the $\mathrm{PO} / 0.005, \mathrm{PO} / 0.01$ and $\mathrm{PO} / 0.015$ groups were not significantly $(\mathrm{P}<0.05)$ altered compared with control. However, there were significant reduction in the groups administered the $V$. amygdalina extract compared with the control (PO/GM) and the PO/0.015 group.

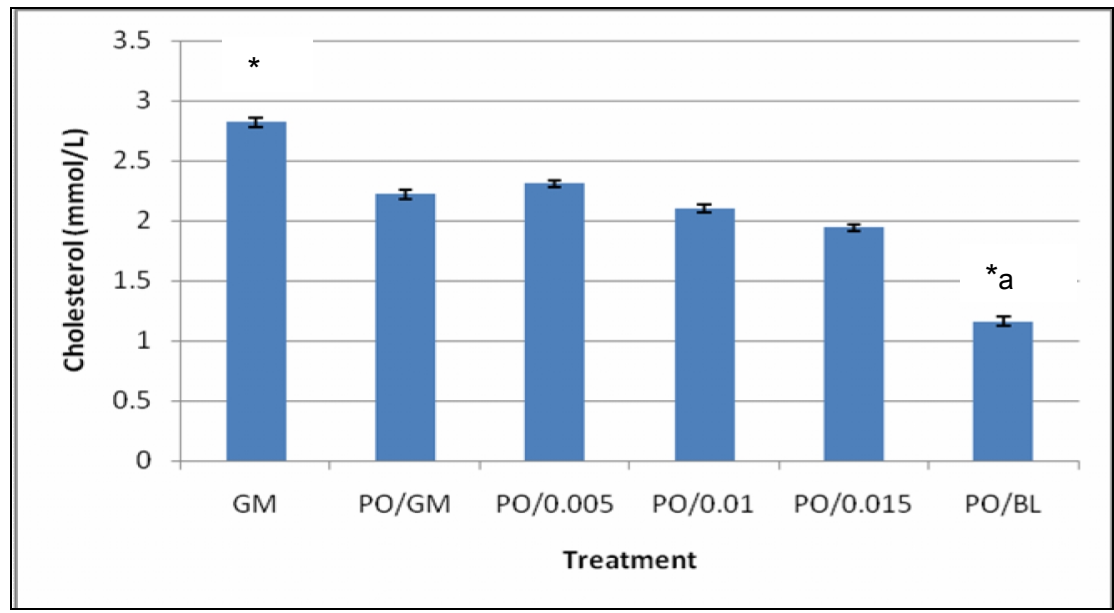

Fig. 6. Effect of red dye adulterated palm oil diets and V. amygdalina on cholesterol levels.

( ${ }^{*}$ significance at $p<0.05$ compared with control, $a=$ significance compared with PO/0.015).

LDL Cholesterol levels were significantly increased in all the groups administered the dye without the extract but significantly reduced in the group administered the extract compared with the control (PO/GM). The PO/BL group also had significant reduction in LDL cholesterol levels compared with the $\mathrm{PO} / 0.015$ group.

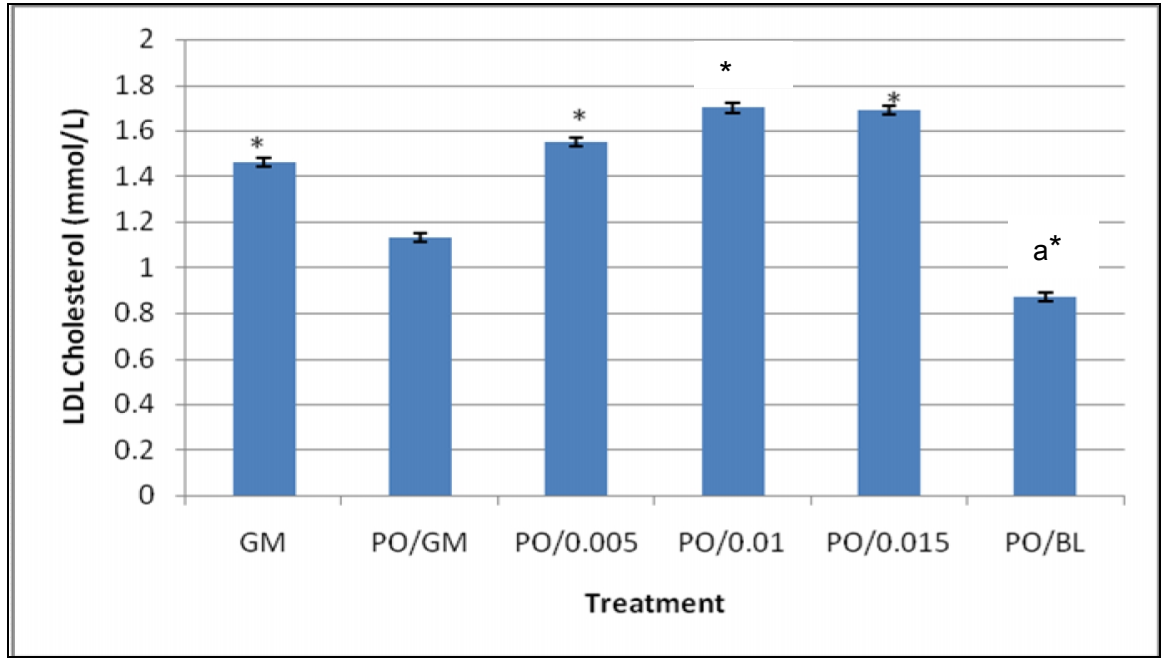

Fig. 7. Effect of red dye adulterated palm oil diets and Vernonia amygdalina extract on LDL cholesterol levels. 
( ${ }^{*}$ significance at $p<0.05$ compared with control, $a=$ significance compared with PO/0.015).

HDL cholesterol levels were significant reduced in all the groups administered the dye and the extract. The ameliorative effect of the $\mathrm{PO} / \mathrm{BL}$ group was not significant.

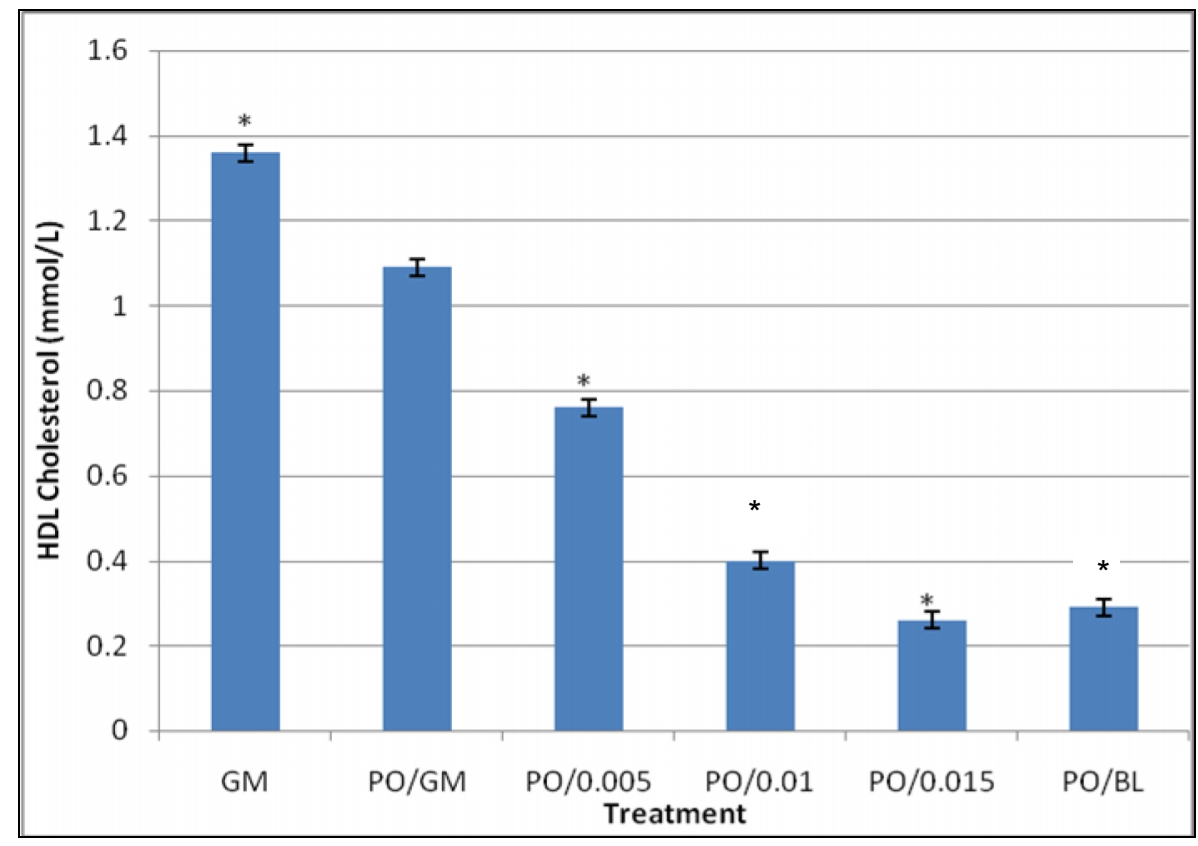

Fig. 8. Effect of red dye adulterated palm oil diets and aqueous extract of $V$. amygdalina on HDL cholesterol levels

( ${ }^{*}$ significance at $p<0.05$ compared with control, $a=$ significance compared with $\mathrm{PO} / 0.015$ )

The loss in body weight of animals in the PO/0.015 group suggests that this dye may be toxic at the $0.015 \%$ dose level and this effect was ameliorated on administration of aqueous extract of $V$. amygdalina. Reduction in feed intake observed in administering the dye at different dose levels and the $V$. amygdalina extract may be due to non palatability of the experimented diet.

Figs. 3-5 shows the effect of $V$. amygdalina on liver and plasma catalase, SOD activities and MDA levels. Liver and plasma catalase and SOD activities were increased, however, there was reduction at the $0.015 \%$ dose level, increased activities of SOD produces higher levels of hydrogen peroxide which is detoxified by catalase, therefore, reduction in catalase may cause accumulation of hydrogen peroxide which in turn induces lipid peroxidation.

V. amygdalina extract increased catalase activity in the PO/BL group suggesting an ameliorative effect; this result is in agreement with the report of Song et al. (2005). Plasma and malondialdehyde levels were significantly increased at all dose levels, lipid peroxidation occurred as a result of oxidative stress this is evident from the result of high doses of MDA and decrease level of catalase activities observed at all levels of dye administration. The measurement of lipid peroxidation is a convenient method to monitor oxidative damage, the enzymic antioxidant defence systems are natural protectors against lipid peroxidation, these 
enzymes prevent generation of hydroxyl radicals and protect cellular constituents from oxidative damage, Ugochukwu et al. (2003).

Figs. 6-8 show the actions of the dye and $V$. amygdalina extract on total blood cholesterol, LDL and HDL cholesterol levels respectively. The dye at all dose levele did not significantly $(P<0.05)$ alter cholesterol levels but significantly increase LDL cholesterol and reduced HDL cholesterol levels, this effect on these lipoproteins may be as a result of the oxidative stress induced by the dye. Bender (2006) postulated that ingesting antioxidants and minimizing free radical exposure may reduce LDL cholesterol concentration. $V$. amygdalina extract reduced total blood cholesterol and LDL cholesterol levels revealing a hypocholesterolemic tendency, this result is in agreement with the report of Egedigwe (2010).

\section{CONCLUSION}

The following can be deduced from this work, firstly, solvent red 24 dye induces oxidative damage to cells, secondly, oxidative damage induces by this dye may increase LDL cholesterol levels which increases the risk of cardiovascular disease incidence. Thirdly, aqueous extract of $V$. amygdalina exert significant protection against oxidative stress induced by this dye and finally, it confirms the hypochesterolmic tendency of $V$. amygdalina extract.

\section{COMPETING INTERESTS}

Authors have declared that no competing interests exist.

\section{REFERENCES}

Adaramoye, O.A., Akintayo, O., Achem, J., Fafunso, M.A. (2008). Lipid lowering effects of meth anole extracts of $V$. amygdalina leaves in rats fed on high cholesterol diet. Vasc. Health Risk Manage, 4, 236-241.

Bender, D.A. (2006). The antioxidant paradox. Damage and Defence. The Biochem, 28(5), 9-12.

Chondrasekharan, N., Sundram, K., Basimol, Y. (2000). Changing Nutritional and Health Perspectives on palm oil. Bru. Int. Med. J., 54, 408-428.

Dees, C., Askari, M., Garrett, S., Gehrs, K., Henley, D., Ardies, C.M. (1997). Estrogenic and DNA - damaging activity of Red No. 3 in human breast cancer cells. Environ. Health Perspect, 3, 625-32.

Edem, D.O. (2002). Palm oil: Biochemical, Physiological aspects, a review, plant foods. Hum. Nutr., 57, 319-314.

Egedigwe, C.A. (2010). Effect of dietary incorporation of $V$. amygdalina and Vernonia colorata on blood lipid profile and relative organ weights in albino rats. MSc Dissertation. Department of Biochemistry, MOUAN, Nigeria.

Ekpo, A., Eseyin, O.A., Ikpeme, A.O., Edoho, E.J. (2007). Studies on some biochemical effects of V. amygdalina in rats. Asia J. Biochem., 2, 193-197.

Friedewald, W.T., Levy, R.T., Fredrickson, D.S. (1972). Estimation of concentration of low density lipoprotein cholesterol in plasma without the use of preparative centrifuge Clin. Chem., 18, 499-502. 
Gutheridge, J.M.C., Wilkin, C. (1982). Cancer dependent hydroxyl radical damage to ascorbic acid. Formation of thiobarbituric acid reactive product. FEBS Lett., 137, 32740.

Igile, G.O., Oleszek, W., Jurzysta, M., Bursa, S., Fanfunso, M., Fasanmade, A.A. (1994). Flavonoids from $V$. amygdalina and their antioxidant activities. J. Agric Food Chem., 42, 2445-2448.

ljeh, I.I., Ejike, C.E.C.C. (2011). Current perspectives on the medicine potentials of $V$. amygdalina Del. J. Med. Plant Res., 5(7), 1051-1061.

Iwu, M.M. (1986). Empirical investigation of dietary plants used in Igbo Ethnomedcine In: Iwu M.M. Plant in indigenous medicine and diet Nina Etkined Redgroove publisher Co. New York, 131-50.

Izevbigie, E.B., Bryant, J.L., Walker, A. (2004). Inhibition of Extracellular signal. Regulated Kinase and Human Breast Cancer Cells. Exp. Biol Med., 229, 163-9.

Izevbigie, E.B. (2003). Discovery of water-soluble anti-cancer agents (edotides) from a vegetable found in Benin city, Nigeria. Exp. Biol. Med., 228, 293-298.

Misra, H.P., Fridovich, I. (1972). The role of superoxide anion in the autoxidation of epinephrine and a single assay for superoxide dismutase. J. Biol. Chem., 247, 31703175.

Owolabi, M.A., Jaja, S.I., Oyekanmi, O.O., Olatunji, O.J. (2008). Evaluation of the antioxidant activity and lipid peroxidation of the leaves of $V$. amygdalina. J. Compl. Integr. Med., 5, DOI, 10, 2202/1550-3540, 1152.

Sinha, K.A. (1972). Colorimetric assay of catalase Ann Biochem., 47, 389-394.

Song, Y.J., Lee, D.Y., Kim, S.N., Lee, K.R., Lee, H.W., Han, J.W., Kang, D.W., Lee, H.Y., Kim, Y.K. (2005). Apoptotic potential of sesquiterpene lactone ergolide, through the inhibition of NF - KB signaling pathway. J. Pharmacol, 57(12), 1587-1591.

Tona, L., Umanga, R.K., Mesia, K., Mushamba, C.T., De Bruyre, T., Apers, S., Hermens, N., Van Miret, S., Pieters, L., Totte, J., Vlietink, A.J. (2004). In intro antiplasmodial activity of extracts and fraction of seven medicinal plants used in the Democratic Republic of Congo. J. Ethnopharmocol, 93, 27-32.

Tsuda, S., Murakami, M., Matsusaka, N., Kano, K., Taniguchi, K., Sasaki, Y.K. (2001). DNA damage induced by red food dyes orally administered to pregnant and male mice. Toxicol. Sci., 61(1), 92-9.

Udensi, E.A., ljeh, I.I., Ogbonna, U. (2002). Effect of traditional processing on the phytochemical and nutrient composition of some local Nigerian leafy vegetables. J. Sci. Tech., 8, 37-40.

Ugochukwu, N.H., Babady, N.E., Cobourne, M., Gasset, S.R. (2003). The effect Gardronema latifolium extracts on serum lipid profile and oxidative stress in heptocytes of diabetic rats. J. Bioscience, 28(1), 1-5.

Wieland, H., Siedel, D. (1981). HDL - Cholesterol estimation. Artzl Lab, 27, 141-54.

Zoppi, F., Fellini, D. (1976). Cholesterol estimation. Clin. Chem., 22, 690-91.

(c) 2012 Kate and Lucky.; This is an Open Access article distributed under the terms of the Creative Commons Attribution License (http://creativecommons.org/licenses/by/3.0), which permits unrestricted use, distribution, and reproduction in any medium, provided the original work is properly cited. 